\title{
The Effect of Proximity to Urban Rail on Housing Prices in Ottawa
}

\author{
Christopher M. Hewitt, M.A., and W. E. (Ted) Hewitt, Ph.D. \\ The University of Western Ontario
}

\begin{abstract}
Increasingly, urban rail transit (URT) is seen as a desirable solution for transportation challenges faced by both urban planners and residents of suburban areas alike. The availability and ease of access to URT, in turn, may result in distortions in local real estate markets. The conventional wisdom, in fact, suggests that construction of urban rail lines serves as a magnet for new housing development and, in turn, can lead to increases in property values in proximity to URT stations. Existing studies have, in good measure, confirmed this belief, but largely on the basis of global area studies that can often mask locally differentiating factors affecting housing prices. Using data from the City of Ottawa, this study seeks to move beyond such analyses by using spatial regression and mapping techniques that reveal that the relationship between URT stations and housing prices is far more complex than is commonly believed. The study demonstrates that while at the macro-level housing prices do vary positively with proximity to URT stations, the relationship is spatially dependent and may be affected by factors unique to specific locales.
\end{abstract}

\section{Introduction}

Urban rail transit ${ }^{1}$ (URT) is an increasingly important feature in major cities insofar as it provides effective transportation to work, leisure activities, and shopping for citizens, particularly in suburban areas (Hess and Almeida 2007). There are also

\footnotetext{
${ }^{1}$ Urban rail transit is any form of "rail [transit] in an urban area, including both heavy and light rail, which may be underground, at level or elevated" (Flyvbjerg 2007, 12).
} 
considerable cost savings accruing to transit users due to the reduced need for personal vehicles, as well as the satisfaction of knowing that one has contributed to positive environmental outcomes. As a consequence, there is often a desire to reside in proximity to URT stations, which provide easy access to the central business district (CBD) and other distant parts of the city.

To date, a number of studies have demonstrated a relationship between proximity to URT and property values (see, for example, Bowes and Ihlanfeldt 2001; Chen et al. 1998; Hess and Almeida 2007; Nelson and McCleskey 1990; Ryan 1999). For the most part, these have confirmed a conventional wisdom that suggests that residing near URT stations can have a positive impact on property values. In a limited number of studies, however, the reverse has been shown; that is, living too close to URT lines may actually depress housing prices under certain circumstances, owing to inconveniences associated with construction and or operation of suburban trains (see, for example, Landis et al. 1995; Nelson 1992; Ryan 2005).

Using advanced spatial regression techniques in combination with detailed mapping and employing a broad range of data from multiple sources, this study seeks to bring clarity to this debate by examining the effect of proximity to URT stations on property values in the city of Ottawa, Canada. In accord with virtually all studies on the topic to date, the study reveals URT location to, indeed, be a sound predictor of housing prices. It is also one, however, that is spatially defined and operates in a somewhat more complex fashion than the existing literature would suggest. Specifically, the research demonstrates that both positive and negative impacts of proximity to URT stations on housing prices are in evidence within the same sampling frame, largely dependent upon spatial location along URT lines.

\section{Current Research on URT Location and Housing Prices}

For this study, 22 analyses conducted between 1973 and 2010 focusing on the relationship between URT location and housing prices were examined. The vast majority of studies were conducted in the United States, some involving multiple cities. About one-quarter were undertaken in other countries, primarily in Asia, with one each in Europe and Latin America. Only two academic studies examining the relationship between the two variables in the Canadian context-both conducted prior to 1985-were discovered, both focusing on the city of Toronto.

Overall, this body of research has presented somewhat divergent tendencies. For the most part, studies have shown a negative relationship between housing prices and distance to the location of URT stations. In other words, housing prices tend to 
decline the farther away from the station the housing property is located. Studies conducted in Boston, Atlanta, Chicago, Portland, and Washington (Baum-Snow and Kahn 2000), Atlanta (Bowes and Inlanfeldt 2001; Nelson and McCleskey 1990), Buffalo (Hess and Almeida 2007), Dallas (Clower and Weinstein 2002), Philadelphia (Slater 1974), Portland (Al-Moasind et al. 1993; Dueker and Bianco 1999; Chen et al. 1998), San Diego (Duncan 2008), San Francisco (Weinberger 2001), Bangkok (Chalermpong 2007), Seoul (Bae et al. 2003), and Shanghai (Pan and Zhang 2008) all affirm this relationship at varying levels of strength. The two studies undertaken in Canada are similarly in accord. A study by Dewees (1976) found that site values increased within one-third mile of transit stations, while Bajic (1983) found that in an around the Spadina surface metro route, housing prices increased by approximately $\$ 2,200$, on average.

In other cases, however, findings have been less conclusive. In Landis et al.'s (1995) four-site examination of San Diego, San Francisco, Sacramento, and San Jose, the relationship between housing prices and distance to URT stations was both negative and positive, suggesting that, in some cases, there is a definite downside to living near transit rail lines, possibly associated with noise pollution and visual esthetics. Similarly mixed results were reported by Nelson (1992) for Atlanta, Ryan (2005) for San Diego, and Munoz-Raskin (2010) for Bogotá.

To some extent, the methodologies employed by these studies may have precipitated this mixed outcome. For the most part using a hedonic model applied to the entire study area, the results almost invariably indicate a single rate of change for property values at increasing distances from URT stations (see, for example, Duncan 2008; Lewis-Workman and Brod 1997; Pan and Zhang 2008). The models thus assume a stationary relationship between the housing prices and other possible explanatory variables across the board. In fact, any number of factors in addition to URT location may affect housing prices differentially in varying locations (see Bae et al. 2003; Hess and Almeida 2007; Munoz-Raskin 2010). This, in turn, suggests that property values likely can and do vary from one station to another, and that the rate of change over distance may also vary accordingly_all pointing to the fact that any relationship that is non-stationary over space will not be modeled particularly well by a single parameter estimate and, indeed, this global estimate may be locally very misleading (see Fotheringham et al. 2002).

Some of the attendant challenges demonstrated by these more limited studies may have been abated had they used a mapping approach in their analyses. In fact, while many do present maps, these are used almost exclusively for reference purposes 
only (Hess and Almeida 2007; Munoz-Raskin 2010; Pan and Zhang 2008; Zhang et al. 1998). ${ }^{2}$ For the most part, presentation of results is restricted to charts and graphs. While helpful, given the possibilities for relationship variance cited above, they simply cannot visualize a spatial relationship effectively enough to catch these.

The primary contribution of this case study to the literature is to bring advanced multiple regression and spatial techniques to a more sophisticated level of understanding of the relationship between housing prices and URT station locations. What it reveals, beyond the basic understanding of the relationship posited within the literature, is that conclusions based on global trends within regions often obscure different, and sometimes opposing, tendencies within defined localities. In revealing these hidden patterns, the study thus provides not only a methodology for future study of this issue, but tools of potential interest and use to urban planners.

\section{Data and Methodology}

The research undertaken for this study was conducted in Ottawa, Canada, located on the south bank of the Ottawa River. Ottawa is Canada's capital city, with a large government employment sector and in the heart of a metropolitan region with a population of approximately 1,000,000. The City's URT line-known as the O-Train-was officially launched in 2001 (Sebree 2002). Currently, the O-Train runs along an eight-kilometer section of track originally constructed by the Canadian Pacific Railway for freight use (Transport Canada 2008). The line extends between the Bayview and Greenboro districts of the city, passing through industrial areas, shopping districts, and more densely-populated neighbourhoods (Transport Canada 2008). The O-Train and URT, in general, have also been subject to a series of studies undertaken by Transport Canada (2008) and the City of Ottawa (Abouhenidy 2008; Leclair 2002; Leclair 2004; City of Ottawa 2010; City of Ottawa et al. 2008) regarding feasibility and future potential.

A large number of sources were used in carrying out the research for this study. The reference data were collected from several sources. The road and rail network information was obtained from the 2003 Ottawa Topographic Mapping dataset maintained by the Serge A. Sauer Map Library at the University of Western Ontario (Ottawa 2003). The land use features were obtained from a secure website database that is distributed through the University's library system (Western 2010). Key points of interest in the city were determined from the results of an O-Train survey

\footnotetext{
${ }^{2}$ The review found that maps were used more frequently as reference maps to present the study area.
} 
conducted in 2002 (Leclair 2002). ${ }^{3}$ Population change and public transit-related population attributes, defined at the census tract (2,500-8,000 inhabitants) and dissemination area (400-700 inhabitants) level, were obtained from Statistics Canada (Statistics Canada 2006a, 2006b, 2008). Reference information from these various sources was plotted using a geographic information system (GIS) developed for the purpose of this study.

Data related to the primary variables under consideration were obtained from two sources. The O-Train route was obtained from the City of Ottawa website (City of Ottawa 2010) as well as reports prepared by the City of Ottawa (see McCormick Rankin Corp. and Delcan 2008). The exact locations of the O-Train stations were identified on Google Maps and then plotted on maps developed for this study. Distance datasets were calculated using GIS-based measurements of the distance (in meters) from each property by street route to the nearest O-Train station. Straight-line distance measurements to several significant "neighborhood" features including water bodies, park land, and the points of interest that were defined previously were included as well.

The property dataset was obtained through written permission from the Ottawa Real Estate Board (REB) (Ottawa Real Estate Board 2010). Housing sales data were collected from specific neighborhoods within the study area, defined as those neighborhoods located within approximately four kilometers of the O-Train route. All sales were recorded for the calendar years 2006 to 2009, coinciding with census data collection and during a period well into the operational phase of the O-Train. Of the more than 80,000 properties populating the study area, the sold properties were examined $(n=3735)$, which were then plotted as individual points on a map using the address mapping feature of ArcMap (Statistics Canada 2006a, 2008). Some duplicate data were present, owing to the fact that a number of properties had been sold more than once. For these properties, the simple mean selling price was calculated and the most recent selling date for that property was recorded. Along with property values, a number of specific residential attributes were also obtained from the Ottawa REB dataset. This included information on the style (apartment, single-detached, townhouse, etc.) and type (bungalow, two-story, split-level) ${ }^{4}$ of single-family dwellings under study and specific features such as number of garages, fireplaces, and so forth that may reasonably affect housing prices.

\footnotetext{
${ }^{3}$ The interest points were South Keys Mall, Preston Street, Downtown, the University of Ottawa, and Carleton University. These are indicated on Figure 1.
}

${ }^{4}$ Dwelling size and type were coded ordinally based on the average value of each category. 
An annotated list of all variables generated from the data referenced above is presented in Table 1. A map of the Ottawa O-Train network is presented in Figure 1, and study points (properties) analyzed as part of this study are presented in Figure 2.

\section{Table 1. Study Variables}

\begin{tabular}{|c|c|c|c|c|}
\hline Variable Type & Variable & Definition & Units & Source \\
\hline Dependent Variable & PRICE & $\begin{array}{l}\text { Amount property } \\
\text { sold for }\end{array}$ & $\$$ & OREB \\
\hline \multicolumn{5}{|c|}{ Independent Variables } \\
\hline $\begin{array}{l}\text { Proximity to O-Train } \\
\text { Station }\end{array}$ & TOTAL_LENG & $\begin{array}{l}\text { Walking distance to } \\
\text { O-Train station }\end{array}$ & $\mathrm{m}$ & $\begin{array}{l}\text { Calculated using } \\
\text { Network Analyst }\end{array}$ \\
\hline \multirow[t]{11}{*}{ Property Variables } & BEDRS_TOT & Number of bedrooms & Count & OREB \\
\hline & BATHS_TOT & Number of bathrooms & Count & OREB \\
\hline & AREA_2 & Area of property & $\mathrm{Ft} 2$ & OREB \\
\hline & TYPEVALUE & Type of house & Value & OREB \\
\hline & STYLEVALUE & Style of house & Value & OREB \\
\hline & BASEMENTVA & $\begin{array}{l}\text { Level of development } \\
\text { in the basement }\end{array}$ & Value & OREB \\
\hline & XGARAGES & Number of garages & Count & OREB \\
\hline & AGE & Age of property & Year & $\begin{array}{l}\text { OREB (2010 - } \\
\text { year built) }\end{array}$ \\
\hline & FIREPLACE & Number of fireplaces & Count & OREB \\
\hline & TOTAL_PA & Amount of parking & Count & OREB \\
\hline & GROSS_TAX & Amount of tax & $\$$ & OREB \\
\hline \multirow[t]{3}{*}{ Location Variables } & Dist_WATR & $\begin{array}{l}\text { Distance to nearest } \\
\text { water feature }\end{array}$ & $\mathrm{m}$ & $\begin{array}{l}\text { Calculated as a } \\
\text { straight line }\end{array}$ \\
\hline & Dist_PARK & $\begin{array}{c}\text { Distance to nearest } \\
\text { park }\end{array}$ & $\mathrm{m}$ & $\begin{array}{l}\text { Calculated as a } \\
\text { straight line }\end{array}$ \\
\hline & Dist_POI & $\begin{array}{c}\text { Distance to point of in- } \\
\text { terest as identified by } \\
\text { O-Train user survey }\end{array}$ & $\mathrm{m}$ & $\begin{array}{l}\text { Calculated as a } \\
\text { straight line }\end{array}$ \\
\hline \multirow[t]{3}{*}{$\begin{array}{l}\text { Neighborhood } \\
\text { Variables }\end{array}$} & Pop_Change & $\begin{array}{c}\text { Change in population } \\
\text { from } 1996-2001 \text { and } \\
2001-2006\end{array}$ & Count & $\begin{array}{l}\text { Calculated from } \\
\text { Census data }\end{array}$ \\
\hline & AVG_INC & Average income & $\$$ & Census data \\
\hline & PUBLIC_TRA & Public transit users & Count & Census data \\
\hline
\end{tabular}




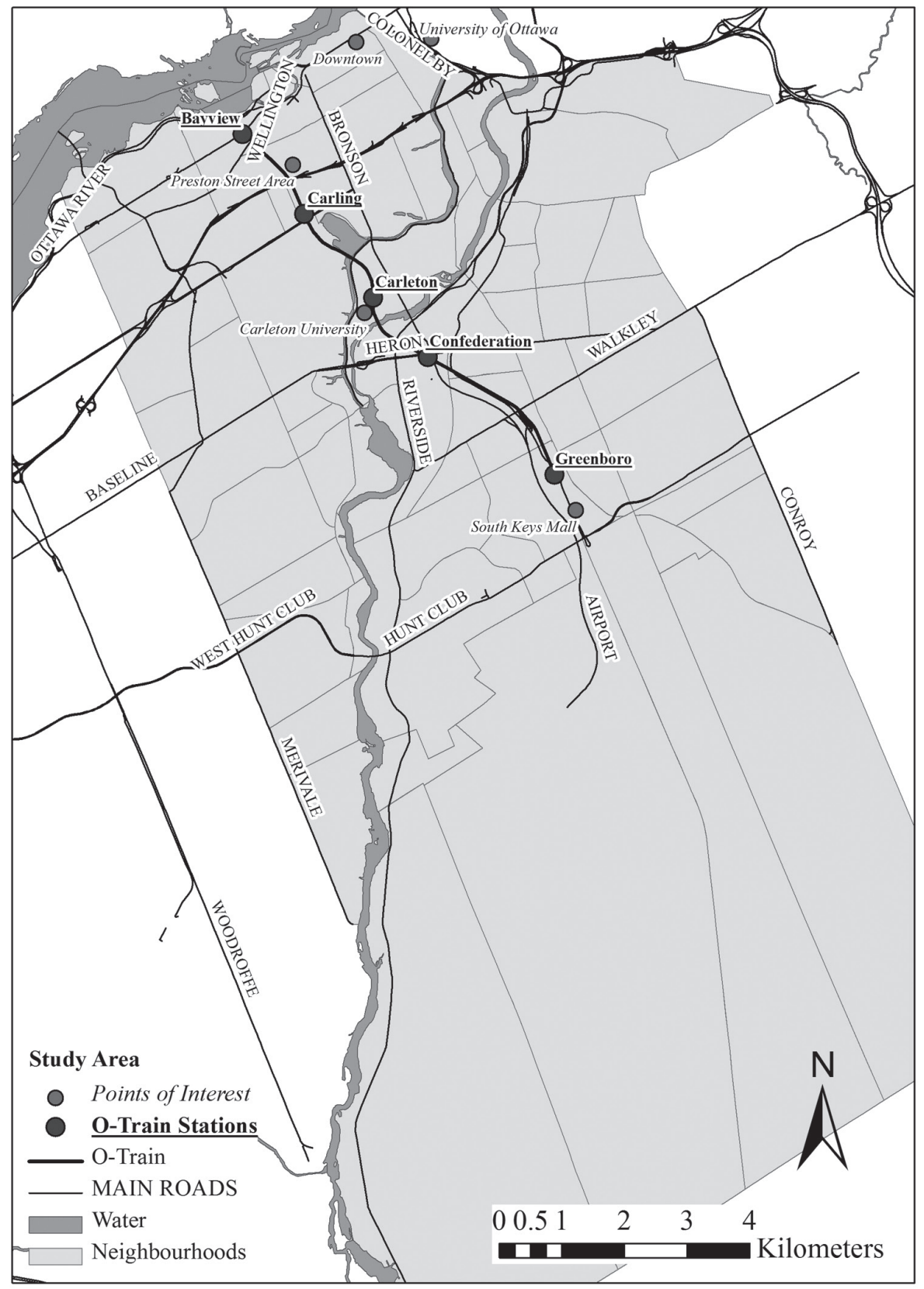

(Leclair, 2002; Ottawa, 2003)

Christopher Macdonald Hewitt

\section{Figure 1. Map of route of 0-Train in Ottawa}




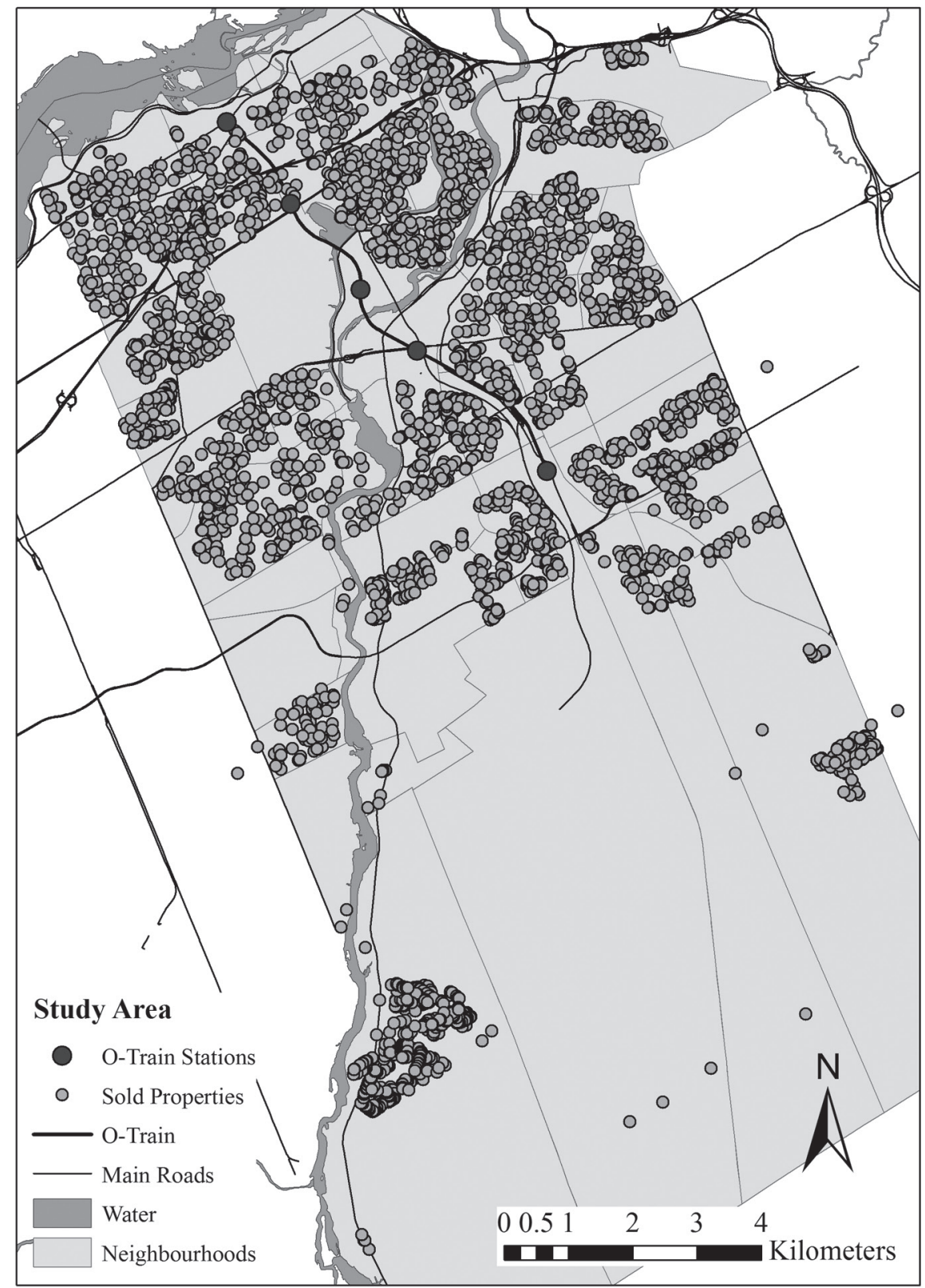

(Ottawa, 2003; Ottawa Real Estate Board, 2008;

Ottawa Real Estate Board, 2010)

Figure 2. Study points 


\section{Results and Analysis}

Using the variables determined in accordance with the process described above, three regression models were generated as part of this study. The initial model is a hedonic ordinary least squares (OLS) analysis similar to what has been undertaken in most studies to date. The second, based upon the OLS findings but moving well beyond the extant literature, is a spatial model. Finally, geographically weighted regression (GWR) models were assessed to examine how relationships between key variables vary locally as opposed to the global relationship for the entire study area.

\section{OLS Regression Model}

The initial linear regression analysis was undertaken with a range of distinct independent variables for which a causal relationship with the dependent variable could be reasonably assumed (see Rogerson 2010). The variables included in this analysis are as they appear in Table 1. Following the initial multiple linear regression modeling, the set of independent variables was refined using the "backward selection" method to include only those ones that were significant (Rogerson 2010). The following independent variables were thus included in the final model: TOTAL_LENG (walking distance to the O-Train stations), BEDRS_TOT (number of bedrooms in property), TYPEVALUE (type of property), STYLEVALUE (style of property), XGARAGES (number of garages on property), and FIREPLACE (number of fireplaces in property).

Table 2 presents the summary characteristics of the multiple regression model, including a series of measures of fit such as the coefficient of determination $R^{2}$, adjusted $R^{2}$, the sum of the squared residuals, the residual variance, and the standard error estimate. Based on these results, it may be observed that the independent variables account for 45 percent of the total variability in the dependent variable.

Table 2. Linear Regression-Summary Statistics

\begin{tabular}{|l|r|c|r|}
\hline Statistic & \multicolumn{1}{|c|}{ Value } & Statistic & \multicolumn{1}{c|}{ Value } \\
\hline R-squared & 0.453 & F-statistic & 514.464 \\
\hline Adjusted R-squared & 0.452 & Prob(F-statistic) & 0.000 \\
\hline Sum squared residual & $4.398 \mathrm{e}+13$ & Log likelihood & -48630.700 \\
\hline Sigma-square & $1.179 \mathrm{e}+10$ & Akaike info criterion & 97275.300 \\
\hline S.E. of regression & 108585 & Schwarz criterion & 97318.900 \\
\hline Sigma-square ML & $1.177 \mathrm{e}+10$ & AICc & 97275.430 \\
\hline S.E of regression ML & 108484 & & \\
\hline
\end{tabular}


Table 3 presents the regression coefficients, standard errors, t-statistics, and associated probability values. The results suggest that all the independent variables are statistically significant. The variables are positively related to the dependent variable, with the exception of the proximity to the O-Train stations (that is, the TOTAL_LENG variable) which is negative, largely in keeping with the findings of previous studies. The results suggest that controlling for the other independent variables that affect pricing, such as styling, number of bedrooms, and inclusion of a fireplace, property values will nevertheless decrease by $\$ 5.33$ for every 1 meter increase in the distance from the O-Train stations. This coefficient lies in the midrange of findings obtained from the other North American studies cited earlier (i.e., less than Bae et al. 2003; Chalermpong 2007; Duncan 2008; Hess and Almeida 2007; Landis et al. 1995; and greater than Al-Mosaind et al. 1993; Chen et al. 1998; Dueker and Bianco 1999).

Table 4 presents several diagnostics on spatial dependence of the residuals. The Moran's I value suggests strong positive autocorrelation, with all other tests significant at a high level. Collectively, these suggest that the residuals are not distributed randomly over the study area. Therefore, the model has violated the spatial dependence assumption. To increase the explanatory power of the regression models, a spatial autocorrelation component was consequently incorporated into the modeling framework using spatial regression models (see Anselin 2005).

\section{Spatial Regression Model}

Spatial regression analysis, in the form of a spatial lag model, was undertaken on the data using the same variables selected in the linear relationship discussed previously.

Table 5 indicates that using this model, the independent variables account for 64.8 percent of the variance in property value. This is a considerable improvement over the OLS model initially explored, as are the indicators in Table 6. In this model, all the coefficients are significant at $p<0.000$, including the spatial autoregressive coefficient (W_PRICE). The regression coefficient associated with the proximity to the O-Train station variable (TOTAL_LENG) is now lower than in the simple OLS model, indicating that controlling for all other variables, property values will drop by $\$ 2.61$ for every $1 \mathrm{~m}$ increase in distance from the O-Train station.

As a final step in this stage of the analysis, an ANOVA was conducted on the sigma square values from Tables 3 and 6. As Table 7 shows, the $F$ value is 1.557, greater than the critical value of 1.00 . This indicates that the spatial lag regression 
Table 3. Linear Regression-Coefficients

\begin{tabular}{|l|r|r|r|c|}
\hline Variable & Coefficient & Std.Error & t-Statistic & Probability \\
\hline CONSTANT & -80537.630 & 10554.120 & -7.631 & 0.000 \\
\hline BEDRS_TOT & 17911.000 & 1962.393 & 9.127 & 0.000 \\
\hline XGARAGES & 34717.710 & 2739.788 & 12.672 & 0.000 \\
\hline TOTAL_LENG & -5.328 & 0.634 & -8.406 & 0.000 \\
\hline STYLEVALUE & 59620.830 & 2493.455 & 23.911 & 0.000 \\
\hline TYPEVALUE & 31880.750 & 1087.044 & 29.328 & 0.000 \\
\hline FIREPLACE & 71168.130 & 3380.540 & 21.052 & 0.000 \\
\hline
\end{tabular}

Table 4. Diagnostics for Spatial Dependence

\begin{tabular}{|l|r|r|r|}
\hline \multicolumn{4}{|c|}{$\begin{array}{c}\text { Diagnostics for Spatial Dependence for Weight Matrix: } \\
\text { Rook Weight (row-standardized weights) }\end{array}$} \\
\hline TEST & \multicolumn{1}{|c|}{ MI/DF } & \multicolumn{1}{c|}{ VALUE } & PROB \\
\hline Moran's I (error) & 0.365 & 38.214 & 0.000 \\
\hline Lagrange Multiplier (lag) & 1 & 1799.436 & 0.000 \\
\hline Robust LM (lag) & 1 & 410.081 & 0.000 \\
\hline Lagrange Multiplier (error) & 1 & 1444.794 & 0.000 \\
\hline Robust LM (error) & 1 & 55.439 & 0.000 \\
\hline
\end{tabular}

Table 5. Spatial Lag Regression-Summary Statistics

\begin{tabular}{|l|c|c|c|}
\hline Statistic & Value & Statistic & Value \\
\hline R-squared & 0.648 & Log likelihood & -47938.300 \\
\hline Sq. correlation & - & Akaike info criterion & 95892.700 \\
\hline Sigma-square & $7.568 \mathrm{e}+9$ & Schwarz criterion & 95942.500 \\
\hline S.E. of regression & 86996.500 & AICc & 95892.639 \\
\hline
\end{tabular}

represents an improvement over the OLS model. At the same time, the spatial lag regression is still considered a semi-local model since it includes local relationships but presents only a global estimate (Fotheringham et al. 2002). To examine the relationship between proximity to the O-Train stations and property values locally, a geographically weighted multiple regression (GWMR) model is required. 
Table 6. Spatial Lag Regression-Coefficients

\begin{tabular}{|l|r|r|r|c|}
\hline Variable & Coefficient & Std.Error & z-value & Probability \\
\hline W_PRICE & 0.586 & 0.014 & 41.007 & 0.000 \\
\hline CONSTANT & -135357.700 & 8594.474 & -15.749 & 0.000 \\
\hline BEDRS_TOT & 16509.350 & 1573.942 & 10.489 & 0.000 \\
\hline XGARAGES & 30345.750 & 2230.256 & 13.606 & 0.000 \\
\hline TOTAL_LENG & -2.605 & 0.515 & -5.057 & 0.000 \\
\hline STYLEVALUE & 29626.170 & 2124.052 & 13.948 & 0.000 \\
\hline TYPEVALUE & 17158.500 & 912.613 & 18.801 & 0.000 \\
\hline FIREPLACE & 50307.240 & 2731.075 & 18.420 & 0.000 \\
\hline
\end{tabular}

Table 7. ANOVA Table Comparing OLS and Spatial Lag Models

\begin{tabular}{|l|c|c|c|c|}
\hline & Sigma Square & Degree of Freedom & Mean Sigma Square & $F$ \\
\hline OLS & $1.179 \mathrm{e}+10$ & 3730 & 3160857.909 & 1.557 \\
\hline Spatial Lag & $7.568 \mathrm{e}+9$ & 3729 & 2029498.525 & \\
\hline Total & $1.936 \mathrm{e}+10$ & 7459 & & \\
\hline
\end{tabular}

\section{GWMR Model}

The GWMR model employed in this study allows for an examination of the variables at the local level. This effectively enables the results to be mapped, which, to date, has not been undertaken in the literature. Therefore, these maps will provide a salient indicator of which neighborhoods are the most or least affected by the presence of the O-Train stations.

In this analysis, results are presented using an "adaptive kernel"- defined by a set number of neighbors per study point as determined from the data. Table 8 presents the output of the optimal model. The first row indicates the number of "neighbors" per study point defining the kernel. This was set at 1000, the maximum number allowed using the ArcMap software. The value of the coefficient of determination, $R^{2}$, for the adaptive model indicates that it explains about 60 percent of the variability in the property values overall. 
Table 8. Adaptive Kernel-Statistics for Multiple Regression Model

\begin{tabular}{|l|c|}
\hline Statistic & Value \\
\hline Neighbors & 1000 \\
\hline Residual Squares & $3.014 \mathrm{e}+13$ \\
\hline Effective Number & 70.936 \\
\hline Sigma & 95755.630 \\
\hline Sigma Square & $9.169 \mathrm{e}+9$ \\
\hline AICc & 86598.684 \\
\hline$R^{2}$ & 0.607 \\
\hline$R^{2}$ Adjusted & 0.599 \\
\hline
\end{tabular}

As expected, however, local variability in $R^{2}$ values is also present, as depicted in Figure 3. Values range in fact from 0.396 to 0.650 . In general, moreover, the model becomes a better fit as one progress further south in the city of Ottawa. The areas where the independent variables explain the least amount of the variation are in the northeast and northwest ranges of the study area.

This relationship is demonstrated in further detail in Figure 4. Here, $t$-values are presented on the left and coefficients on the right. The $t$-value map indicates that the values to the east and west in near proximity to the O-Train in the north end of the line as well as in the mid-south are significant at the $\alpha=0.05$ level and greater $(t>1.96)$. The positive values indicate that as distance increases, property value increases. The coefficients indicate that this increase varies between $\$ 12.07$ and $\$ 39.34$ more per meter distant from the O-Train stations. 


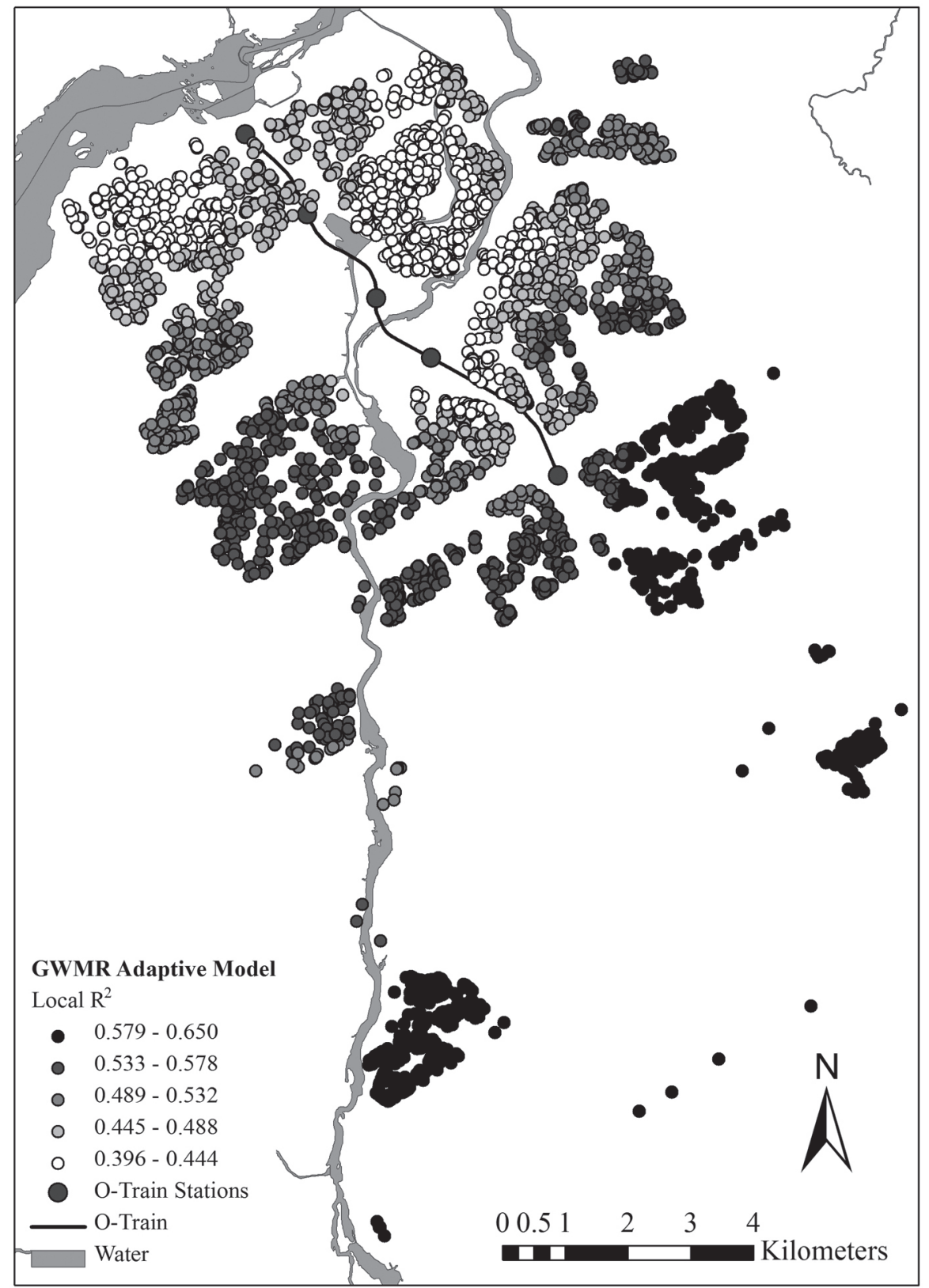

Ottawa, 2003; Ottawa Real Estate Board, 2010

Figure 3. GWMR adaptive model-local $\mathbf{R}^{2}$ 


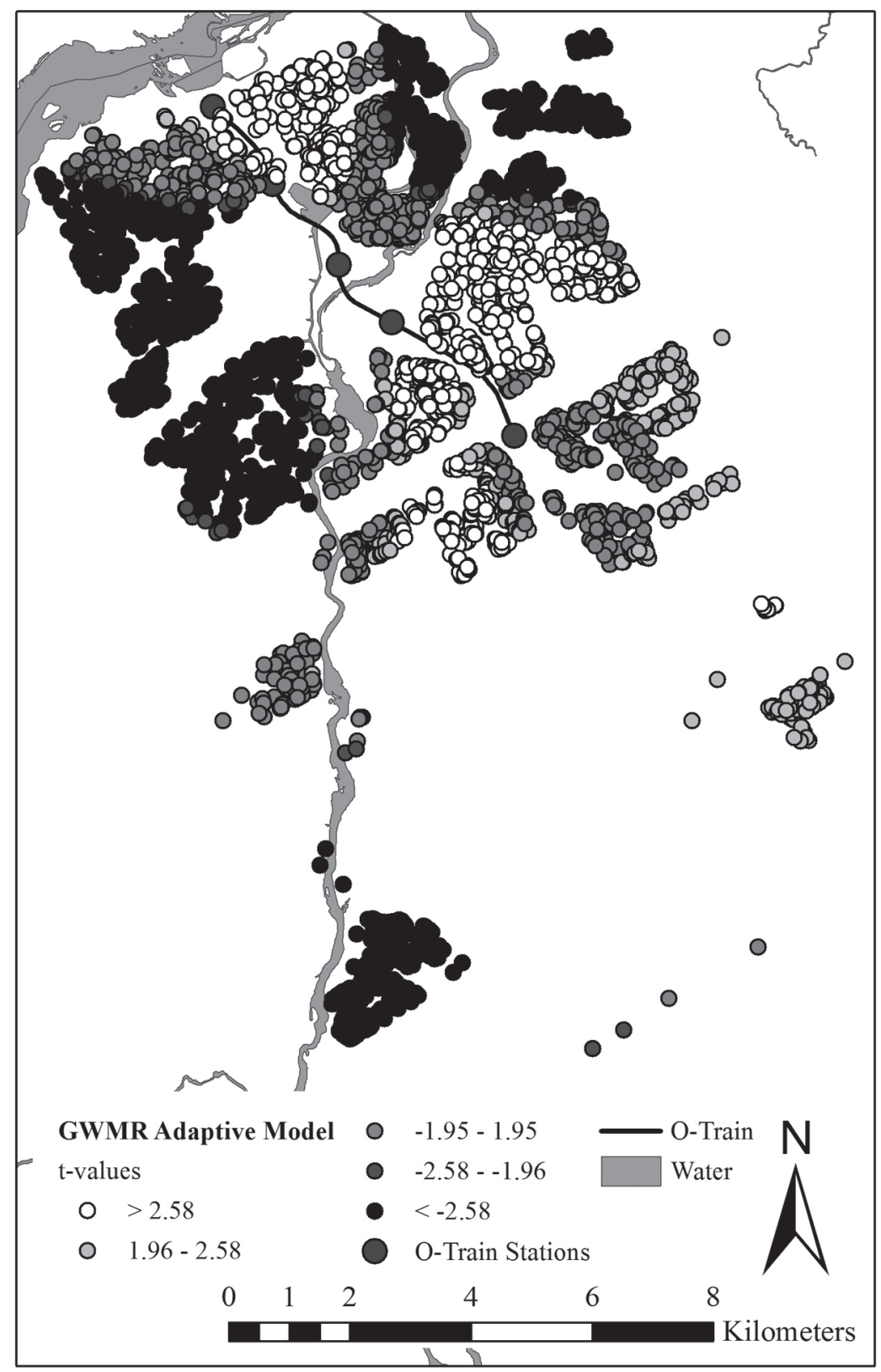

Ottawa, 2003; Ottawa Real Estate Board, 2010

Figure 4a. GWMR adaptive model-t-values and coefficients for proximity to 0-Train Station variable 


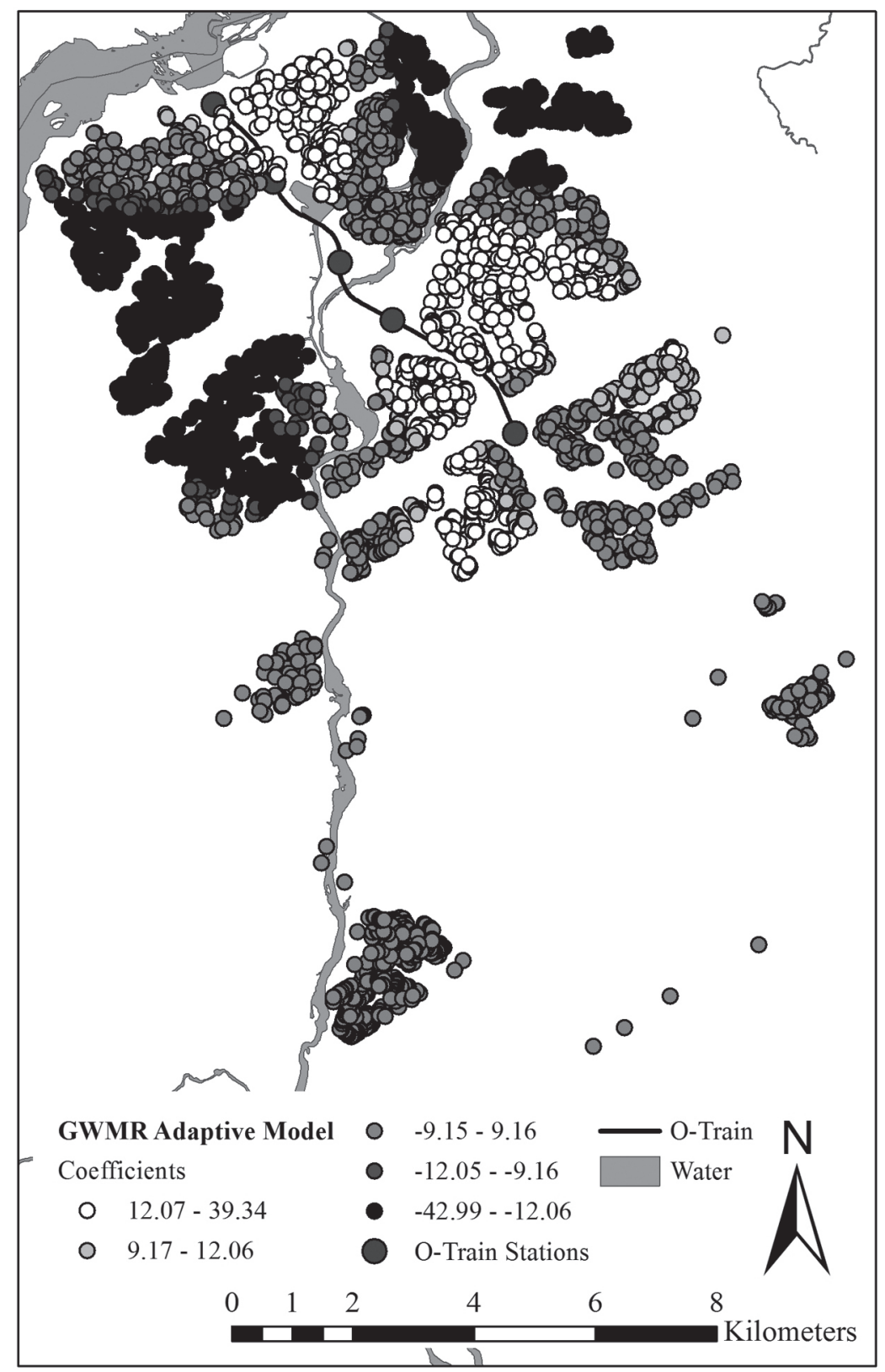

Ottawa, 2003; Ottawa Real Estate Board, 2010

Figure $4 b$. GWMR adaptive model-t-values and coefficients for proximity to $\mathbf{0}$-Train Station variable 
The relationship is the reverse at a greater distance from the track in a broad band along the eastern border of the study area and in areas to the northeast. Here, the values are significant at the $\alpha=0.05$ level and greater $(t<-1.96)$. This implies that as distance increases property values decrease. According to the coefficient map, properties will cost between $\$ 12.06$ and $\$ 42.99$ less per meter away as one moves away from the O-Train stations.

In all other areas-particularly to the far south as well as the mid-north and northwest in close proximity to the O-Train-the relationship is insignificant $(-1.95<t$ $<1.95)$ and the coefficients $(c)$ are the smallest $(-9.15<c<9.16)$. These, then, are areas where the presence of $\mathrm{O}$-Train stations is least likely to affect property values in either a positive or negative direction.

The improvement of the GWMR model over the OLS model can be tested with an ANOVA. As Table 9 reveals, an ANOVA run on the sigma square values from Tables 2 and 8 yielded an $F$ value of 1.286. Since $F>1.00$, the adaptive GWMR model can be considered an improvement to the OLS model.

\section{Table 9. ANOVA Table Comparing Multiple OLS and Adaptive GWMR Models}

\begin{tabular}{|l|c|c|c|c|}
\hline & Sigma Square & Degrees of Freedom & Mean Sigma Square & F \\
\hline OLS & $1.179 \mathrm{e}+10$ & 3730 & 3160857.909 & 1.286 \\
\hline Adaptive GWMR & $9.169 \mathrm{e}+9$ & 3730 & 2458176.944 & \\
\hline Total & $3.509 \mathrm{e}+10$ & 7460 & & \\
\hline
\end{tabular}

The ANOVA can similarly test if the GWMR model is an improvement over the spatial lag model. Table 10 shows the ANOVA calculated for the $F$ value to be 0.826 for the sigma square values shown in Tables 5 and 8 . Therefore, the value $F<1.00$ suggests that the adaptive GWMR is not an improvement to the spatial lag model.

Table 10. ANOVA Table Comparing Multiple Spatial Lag and Adaptive GWMR Models

\begin{tabular}{|l|c|c|c|l|}
\hline & Sigma Square & Degrees of Freedom & Mean Sigma Square & F \\
\hline Spatial Lag & $7.568 \mathrm{e}+9$ & 3729 & 2029498.525 & 0.826 \\
\hline Adaptive GWMR & $9.169 \mathrm{e}+9$ & 3730 & 2458176.944 & \\
\hline Total & $3.509 \mathrm{e}+10$ & 7459 & & \\
\hline
\end{tabular}




\section{Conclusions}

The vast majority of previous studies examining proximity to URT stations and property value employed an OLS approach, while very few studies considered a spatial model. In addition, they tended uniformly to report global relationships. None effectively used more advanced techniques such as geographically weighted multiple regression (GWMR) to examine the relationship between the residential property values and proximity to URT stations at the local level. In addition, very few studies displayed their results as maps.

Given those limitations of previous studies, the aim of this research was to provide a comprehensive analysis of the relationship between the property values and proximity to URT stations using a variety of regression models and GIS tools.

This study established that the results of the hedonic OLS model used here (and by implication, other OLS models employed previously in the literature) were insufficient for drawing conclusions about the relationship between proximity to O-Train stations and property values in Ottawa. This insufficiency was due to the problem of spatial autocorrelation of the residuals from the regression model. To correct for this, further analysis determined that a spatial model would be a better tool for analyzing the relationship. However, while identifying the existence of likely spatial differences, the model was able to provide only a global analysis of the relationship between proximity to the O-Train stations and property values. Consequently, a GWMR model was applied to analyze more directly the relationship locally. The study demonstrated, in fact, that the spatial lag model was the "optimal" method for examining the relationship both locally and globally.

In terms of its overall findings, the study demonstrated that while not the most important factor in determining house prices, there is a statistically significant relationship between proximity to the O-Train stations and property values in the City of Ottawa. The results of the global regression analyses also indicated-in keeping with a large number of studies within the extant literature-that the relationship is negative; that is, the property values tend to decrease with increasing distance from the O-Train stations.

More importantly, however, the study revealed that such elementary analysis effectively hides a more complex relationship between the two variables under study. Further analysis clearly demonstrated that this is a relationship that also varies spatially; that is, the strength and direction of the relationship is locationally dependent, with housing prices in some areas affected positively and in other areas 
negatively by distance from the O-Train stations. Specifically, many neighborhoods in closest proximity to the O-Train route saw a negative impact on housing prices, while many areas located further away experienced a significant increase. This, in turn, tends to support the finding of a small minority of studies to date that have been drawn to similar conclusions, albeit with less sophisticated tools (see, for example, Landis et al. 1995; Nelson 1992; Munoz-Raskin 2010).

There are several explanations potentially accounting for this result. One possible factor-mentioned frequently in the literature-relates to noise pollution and potentially bus and car traffic associated with the operation of the O-Train line. It may simply be that housing in proximity to the line is less desirable as homeowners seek the refuge of quieter streets located further away from the line. An associated concern may be related to the history and potential future of the O-Train service. Before 2001, the O-Train line was used for freight trains. In fact, the track is still considered a freight line since the Canadian Pacific Railway maintains ownership (Transport Canada 2008). Therefore, property values may remain depressed in proximity to the O-Train line due to the possibility of a failure of the O-Train venture and a perceived eventual return to freight train travel through the corridor. Properties of the surrounding area affecting affluence and or desirability of neighborhoods may also have an influence, such as distance from industrial parks, the CBD, parks, malls, and airports. Examination of all of these myriad influences remains, however, beyond the scope of this study. Further research may help to clarify the precise nature of these relationship variables and their correlation with the two primary variables.

Based upon this study, however, one outcome is clear-controlling for the myriad of factors that help determine property values, proximity to URT stations does have an impact on pricing, but one that varies depending on residential location. Along with its contribution to knowledge in this field, at very least, then, such information may be relevant and beneficial to future urban development in Ottawa and other regions where urban rail transit already exists or is planned. For urban planners, the study suggests the following cautions:

1. Depending upon the neighborhood, location of URT stations may not positively affect property values and, thus, not be uniformly welcomed by local homeowners (or local-level political representatives).

2. Desirability of residing close to URTs and, thus, volume of usage of transit systems may not be uniform throughout the system.

3. Zoning in proximity to URT stations needs to take into account local features 
as well as factors associated with access to transit to take full advantage of land rents.

\section{Acknowledgments}

The authors would like to thank Carol Mallett for her assistance in providing access to the Ottawa real estate database and Dr. Jacek Malczewski for advice provided during both the data collection and analysis phases of this study.

\section{References}

Abouhenidy, M. 2008. Moving forward with rapid transit. White Paper, 34-40.

Al-Mosaind, M. A., K. J. Dueker, and J. G. Strathman. 1993. Light rail transit stations and property values: A hedonic price approach. Transportation Research Record 1400: 90-94.

Anselin, L. 2005. Exploring spatial data with GeoDa ${ }^{\mathrm{TM}}$ : A workbook. Center for Spatially Integrated Social Science, Urbana, Illinois.

Bae, C.-H. C., M.-J. Jun, and H. Park. 2003. The impact of Seoul's Subway Line 5 on residential property values. Transport Policy 10: 85-94.

Bajic, V. 1983. The effects of a new subway line on housing prices in Metropolitan Toronto. Urban Studies 20: 147-158.

Baum-Snow, N. and M. E. Kahn. 2000. The effects of new public projects to expand urban rail transit. Journal of Public Economics 77: 241-263.

Bowes, D. R., and K. R. Ihlanfeldt. 2001. Identifying the impacts of rail transit stations on residential property values. Journal of Urban Economics 50: 1-25.

Chalermpong, S. 2007. Rail transit and residential land use in developing countries: Hedonic study of residential property prices in Bangkok, Thailand. Transportation Research Record 2038: 111-119.

City of Ottawa, McCormick Rankin Corp., and Delcan. 2008. Transportation master plan infrastructure requirement study: Development of a downtown transit solution and network implications. Retrieved February 11, 2010, from www.ottawa.ca. 
City of Ottawa. 2010, Last Update. City of Ottawa [Homepage for City of Ottawa, Canada]. Retrieved July 21, 2010, from www.ottawa.ca.

Clower, T. L., and B. L. Weinstein. 2002. The impact of Dallas Texas Area Rapid Transit light rail stations on taxable property valuations. Australasian Journal of Regional Studies 8(3): 389-400.

Dewees, D. 1976. The effect of a subway on residential property values in Toronto. Journal of Urban Economics 3: 357-369.

Dueker, K. J., and M. J. Bianco. 1999. Light rail transit impacts in Portland: The first ten years. Transportation Research Record 1685: 171-180.

Duncan, M. 2008. Comparing rail transit capitalization benefits for single-family and condominium units in San Diego, California. Transportation Research Record 2067: 120-130.

Flyvbjerg, B. 2007. Cost overruns and demand shortfalls in urban rail and other infrastructure. Transportation Planning and Technology 30: 1, 9-30.

Fotheringham, A. S., C. Brunsdon, and M. Charlton. 2002. Geographically Weighted Regression: The Analysis of Spatially Varying Relationships. Chichester: John Wiley \& Sons, Ltd.

Hess, D. B., and T. M. Almeida. 2007. Impact of proximity to light rail rapid transit on station-area property values in Buffalo, New York. Urban Studies 44(5/6): 1041-1068.

Landis, J., S. Guhathukurta, W. Huang, M. Zhang, B. Fukuji, and S. Sen. 1995. Rail transit investments, real estate values, and land use change: A comparative analysis of five California rail transit systems. Research Report No. 48, Institute of Urban and Regional Studies, University of California, Berkeley.

Leclair, R. T. 2002. O-Train evaluation report. Retrieved October 26, 2010, from www.ottawa.ca.

Leclair, R. T. 2004. The O-Train: The straight facts. Retrieved October, 2010, from www.ottawa.ca.

Lewis-Workman, S., and D. Brod. 1997. Measuring the neighborhood benefits of rail transit accessibility. Transportation Research Record 1576: 147-153.

Munoz-Raskin, R. 2010. Walking accessibility to bus rapid transit: Does it affect property values? The Case of Bogota, Colombia. Transport Policy 17: 72-84. 
Nelson, A. C. 1992. Effects of elevated heavy rail transit stations on house prices with respect to neighborhood income. Transportation Research Record 1359: 127-132.

Nelson, A. C., and S. J. McCleskey. 1990. Improving the effects of elevated transit stations on neighborhoods. Transportation Research Record 1266: 173-180.

Ottawa. 2003. 1:10,000 scale topographic data. [computer file]. Ottawa: City of Ottawa.

Ottawa Real Estate Board. 2010. Last Update. MLXchange [Real Estate Website for Property Listings]. Retrieved June, 2010, from http://oreb.mlxchange.com/.

Pan, H., and M. Zhang. 2008. Rail transit impacts on land use: Evidence from Shanghai, China. Transportation Research Record 2048: 16-25.

Rogerson, P. A. 2010. Statistical Methods for Geography. London: Sage Publications Ltd.

Ryan, S. 1999. Property values and transportation facilities: Finding the transportation-land use connection. Journal of Planning Literature 13: 412-427.

Ryan, S. 2005. The value of access to highways and light rail transit: Evidence for industrial and office firms. Urban Studies 42(4): 751-764.

Sebree, G. M. 2002. O-Train: Is light rail on the verge of revolution? Trains 6211: 30-31.

Slater, P. B. 1973. Spatial and temporal effects in residential sales prices. Journal of the American Statistical Association 68343: 554-560.

Slater, P. B. 1974. Disaggregated spatial-temporal analysis of residential sales prices. Journal of the American Statistical Association 69346: 554-560.

Statistics Canada. 2006a. Census of population, 2006: Cartographic boundary, digital boundary, ecumene, road network, road network and geographic attribute files/. Census of population, 2006: Maps [machine readable data file]. Ottawa, ON: Statistics Canada (producer), Statistics Canada, Data Liberation Initiative (distributors).

Statistics Canada. 2006b. Census of population, 2006: Geosuite: Population (2006/2001) and dwelling counts (2006) for census tracts [machine readable data file]. Ottawa, ON: Statistics Canada (producer), Statistics Canada, Data Liberation Initiative (distributors). 
Statistics Canada. 2008. Census of population, 2006: Table 94-581-XCB2006002: Profile for Canada, provinces, territories, census divisions, census subdivisions and dissemination areas [machine readable data file]. Ottawa, ON: Statistics Canada (producer), Statistics Canada, Data Liberation Initiative (distributors).

Statistics Canada, 2010. 2006 Census Dictionary. Retrieved June, 10, 2010, from http://www12.statcan.gc.ca/census-recensement/2006/ref/dict/index-eng. $\mathrm{cfm}$.

Transport Canada, 2008. O-Train light rail project. Case Studies in Sustainable Transportation, Case Study 7, 1-9.

Weinberger, R. R. 2001. Light rail proximity: Benefit or detriment in the case of Santa Clara County, California? Transportation Research Record 1747: 104-113.

Western. 2010. Equinox data delivery system [Internet-based source for census data]. Retrieved June, 2010, from: http://equinox.uwo.ca/EN/BasicSearch.asp.

Zhang, M., Q. Shen, and J. Sussman. 1998. Job accessibility in the San Juan Metropolitan Region: Implications for rail transit benefit analysis. Transportation Research Record 1618: 22-31.

\section{About the Authors}

Christopher M. Hewit (chewitt4@uwo.ca) is a Ph.D. student in Geography at the University of Western Ontario in London, Canada. His interests include contemporary transportation geography and historical GIS. Currently, he is studying the medieval landscape of the Battle of Hastings in southern England, and he recently published an article on this topic entitled "The Geographic Origins of the Norman Conquerors of England" in Historical Geography.

W. E. (TED) HEWITT (hewitt@uwo.ca) is Professor of Sociology at the University of Western Ontario and Public Policy Scholar at the Woodrow Wilson International Center for Scholars in Washington. He has published extensively on issues related to urban social movements, local government, and international cooperation for urban development. His work has appeared in monographs, edited works, and a range of academic journals including Cities, Habitat International, Journal of Developing Areas, and Third World Quarterly. 